\title{
Mouhy, La Paysanne parvenue, ou les Mémoires de la marquise de L. $V$.
}

\section{Franco Piva}

\section{(2) OpenEdition}

1 Journals

\section{Édition électronique}

URL : http://journals.openedition.org/studifrancesi/27607

DOI : $10.4000 /$ studifrancesi.27607

ISSN : 2421-5856

Éditeur

Rosenberg \& Sellier

\section{Édition imprimée}

Date de publication : 31 décembre 2006

Pagination : 605-606

ISSN : 0039-2944

\section{Référence électronique}

Franco Piva, «Mouhy, La Paysanne parvenue, ou les Mémoires de la marquise de L. V. », Studi Francesi [En ligne], 150 (L | III) | 2006, mis en ligne le 30 novembre 2015, consulté le 08 novembre 2020. URL : http://journals.openedition.org/studifrancesi/27607 ; DOI : https://doi.org/10.4000/studifrancesi. 27607

Ce document a été généré automatiquement le 8 novembre 2020.

\section{(c)}

Studi Francesi è distribuita con Licenza Creative Commons Attribuzione - Non commerciale - Non opere derivate 4.0 Internazionale. 


\title{
Mouhy, La Paysanne parvenue, ou les Mémoires de la marquise de L. V.
}

\author{
Franco Piva
}

\section{RÉFÉRENCE}

MоUнY, La Paysanne parvenue, ou les Mémoires de la marquise de L. V.. Edition présentée, établie et annotée par Henri coulET, Paris, Editions Desjonquères («Collection XVIIIe siècle»), 2005, pp. 497.

1 «Journaliste, correspondant littéraire, auteur de nouvelles à la main et de rapports destinés à la police, historien du théâtre, informateur de Voltaire qui l'aida financièrement et se brouilla avec lui, poligraphe besogneux», autore di un certo numero di romanzi che al loro tempo incontrarono a volte un successo maggiore di quello ottenuto da opere ora assai più famose, Mouhy è, oggi, uno scrittore quasi dimenticato. La critica l'ha, d'altra parte, posto, come ha fatto osservare Henri Coulet, «au deuxième ou troisième rang». La Paysanne parvenue è certamente una delle sue opere più significative. La sua lettura, resa possibile dalla riedizione, accurata ed in grafia moderna, che ne ha dato, molto opportunamente, Henri Coulet, può consentire al lettore non solo di farsi un'idea abbastanza precisa delle qualità e dei difetti dell'opera, ma anche della giustezza, o meno, della condanna che la critica ha, forse un po' troppo affrettatamente, espresso su uno scrittore che, se non ha le qualità dei grandissimi, merita tuttavia molta più attenzione di quanto la critica gliene abbia concessa fin dai primi anni dell'Ottocento.

2 Un po' per pigrizia, un po' per la fretta con la quale è costretto a scrivere, Mouhy non mira prima di tutto all'originalità; spesso prende spunto o ispirazione da opere precedenti. La cosa vale anche per la Paysanne parvenue. «La Paysanne parvenue rappelle par son titre et par sa tonalité Le Paysan parvenu, par son héroïne et par son dessein général la Vie de Marianne - osserva Coulet -. Jeannette, comme le Jacob de Marivaux, est née et a été élevée à la campagne, dans une famille bien plus pauvre que celle de 
Jacob, et comme lui elle découvre le luxe, la complexité, les dangers et les ressources de la vie dans le monde des châteaux et de la grande ville; comme Marianne, elle excite par sa sensibilité et ses qualités l'affection protectrice d'une dame de l'aristocratie; par son charme le désir d'un libertin et celui d'un parvenu qui croit sa conquête facile; par sa beauté, par sa tendresse et par sa vertu l'amour profond et fidèle du jeune seigneur qui finalement l'épousera». La Paysanne parvenue non è, tuttavia, una semplice, e somme toute banale imitazione del Paysan parvenu e della Vie de Marianne. Meno profonda di Marianne, meno lucida di Jacob, Jeannette ha una sua personalità ben precisa, che Coulet ha posto chiaramente in evidenza e finemente analizzato nella sua bella «Introduction", così come il romanzo ha, al di là degli emprunts, una sua originalità. Il fatto è che Mouhy è, malgrado i difetti ed i limiti, uno scrittore di razza. «On peut prétendre que Mouhy n'a ni la profondeur métaphysique de Prévost, ni l'intelligence et la sensibilité de Marivaux, ni la perspicacité critique de Crébillon, ni même l'humour de Lesage, mais l'on ne peut pas dire qu'il n'est pas lui-même un vrai romancier, qui sait construire une œuvre, coordonner tous les éléments divers qui entrent dans sa composition, faire vivre de nombreux personnages qui réagissent nécessairement les uns sur les autres, saisir le détail concret, le geste, le local (l'illusion de la réalité est bien plus forte chez lui que chez aucun des romanciers de son temps), maintenir en suspens l'intérêt du lecteur et laisser ce lecteur devant le roman comme devant l'oppressant et parfois incompréhensible monde réel», osserva a questo proposito Coulet. Con queste premesse, il lettore può accostarsi con fiducia al romanzo, sicuro di non rimanere deluso, certo anzi di scoprire un'opera, ed uno scrittore, troppo ingiustamente trascurati. La Paysanne parvenue fu del resto continuamente ristampata per tutto il Settecento e ad essa guardarono non soltanto scrittori di modesto talento, come l'abbé Lambert e Gaillard de la Bataille, che l'imitarono, in due loro opere, ma anche scrittori assai più importanti, e coscienti delle loro qualità, quali, oltre allo stesso Marivaux, Richardson che di essa si ricordò nel costruire la sua Pamela, e lo stesso Rousseau che ne riprese un episodio nella Nouvelle Héloïse, a segno dell'interesse che l'opera ha suscitato tra i contemporanei e degli indubbi meriti che, al di là degli altrettanto indubbi difetti, essa comportava, e comporta. 